\title{
Biosynthesis Significance of Iridoids in Chemosystematics
}

\author{
M. Isabel Sampaio-Santos ${ }^{a} *$ and M. Auxiliadora C. Kaplan ${ }^{b}$ \\ ${ }^{a}$ Departamento de Produtos Naturais e Alimentos, Faculdade de Farmácia, Universidade Federal do \\ Rio de Janeiro, Cidade Universitária, 21941-590, Rio de Janeiro - RJ, Brazil \\ ${ }^{\mathrm{b}}$ Núcleo de Pesquisas de Produtos Naturais, Centro de Ciências da Saúde, Universidade Federal do \\ Rio de Janeiro, Cidade Universitária, 21941-590, Rio de Janeiro - RJ, Brazil
}

\begin{abstract}
Iridóides são substâncias monoterpenoídicas formadas em plantas por uma ciclização alternativa do pirofosfato de geranila. A estrutura química dessas substâncias é baseada no esqueleto ciclopentano-[C]-pirano, iridóides carbocíclicos, e a clivagem oxidativa da ligação 7,8 do anel ciclopentano fornece os chamados secoiridóides. Sob o aspecto biogenético, os iridóides são biossintetizados a partir do cátion iridodial e diversificam-se em 27 vias diferentes. Iridóides têm sido usados como marcadores quimiotaxonômicos para as superordens Corniflorae, Gentianiflorae, Loasiflorae e Lamiiflorae. O número e a natureza dos iridóides encontrados no Reino Vegetal são indicativos da complexidade das vias envolvidas na sua biossíntese. Em Quimiossistemática, os iridóides representam um marcador importante em classificação vegetal, filogenia e evolução.
\end{abstract}

\begin{abstract}
Iridoids represent a large group of monoterpenoid compounds that apparently seem to be formed in plants by an alternative cyclization of geranyl diphosphate. The structures of these compounds are based on a cyclopentan-[C]-pyran skeleton, carbocyclic iridoids, and oxidative cleavage at the 7,8bond of the cyclopentane moiety affords the so called secoiridoids. On biogenetic grounds the iridoid formation may be considered to start from iridodial cation and follow diversification through 27 different routes. Iridoids have been used as chemical markers for the Corniflorae, Gentianiflorae, Loasiflorae and Lamiiflorae superorders. The number and nature of the iridoids occurring in plants are a measure of the complexity of the routes involved in their biosynthesis. In chemosystematics, the value of iridoid character shows important significance in plant classification, phylogeny and evolution
\end{abstract}

Keywords: Iridoids, chemosystematic, biosynthesis.

\section{Introduction}

Iridoids are monoterpenoids based on a cyclopentan[C]-pyran skeleton (Figure 1), which may consist of ten, nine, or rarely eight carbon atoms in which $\mathrm{C}_{11}$ is more frequently missing than $\mathrm{C}_{10}$. Oxidative cleavage at 7,8bond of the cyclopentane moiety affords the so called secoiridoids ${ }^{1-3}$. The stereochemical configurations at $\mathrm{C}_{5}$ and $\mathrm{C}_{9}$ leading to cis fused rings is common to all iridoids containing the basic carbocyclic- or seco-skeleton in non-rearranged form. The last steps in the biosynthesis of iridoids are considered to be O-glycosylation and Oalkylation. The concern of this paper is the significance of iridoid biosynthesis in chemosystematic studies or, in other words, the use the biosynthetic routes as tools for understanding the systematic positioning of iridoid containing plants.

*e-mail: sampaio@pharma.ufrj.br

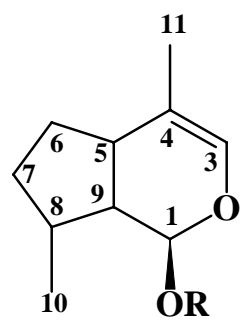<smiles>C=CC1C(C)=CO[C@@H](O)C1CC</smiles>

Figure 1. Numbering system for iridoid compounds ( $R=H$ or glucose).

Micromolecular plant chemosystematics is a field involving the biological relationships of organisms, on the one hand, and chemical characters on the other. The chemical characters vary with the biogenetic classes of compounds, frequency of occurrence and chemical polarization or gradient extension of molecular evolution (oxidation state and skeletal specialization), but they do not stand on presence/absence criteria 4 .

Iridoid biosynthesis pathways have been well reviewed elsewhere ${ }^{5,6}$. 


\section{Recent trends in iridoid biosynthesis}

Numerous experiments using labeled compounds in vivo and incorporation of radioactive compounds have established geranyl pyrophosphate as the precursor of iridoids ${ }^{7-9}$. It was suggested that the cyclization of an acyclic monoterpene to the iridane skeleton may involve a double Michael-type addition of geranyl pyrophosphate to yield iridodial ${ }^{10,11}$. Iridoids may be envisaged as a biogenetic alternative to the typical monoterpenes and there is evidence for an inverse relationship between the production of monoterpenes and iridoids in the Lamiaceae family ${ }^{12}$. The secoiridoids form the largest class of iridoid compounds found both as glucosides and, more commonly, in modified forms as secoiridoid-indole alkaloids. In the present analysis, indoleterpenic alkaloid derivatives are not considered.

The use of labelled iridoids in order to establish steps of the biosynthetic route has been well reported. Results of these experiments are summarized in Figure 2. Feeding experiments with deuterium-labelled 8-epi-iridodial (1), 8-epi-iridotrial (2) and 8-epi-iridotrial glucoside (boschnaloside) (3) gave incorporation into both harpagide (4) and aucubin (5) in Scrophularia umbrosa (Scrophulariaceae), whereas the same compounds did not show significant incorporation into $\mathbf{5}$ in Buddleya albiflora (Buddleyaceae). In the experiments with $B$. albiflora, the deuterium-labelled precursor 8-epi-deoxyloganic acid (6) gave an incorporation of $5 \%$, whereas no significant incorporations were seen after feeding with 1, 2 and 3. The negative results may suggest another probable intermediate in the biosynthesis of 5 in plants ${ }^{13,14}$. These facts however did not show $\mathbf{3}$ as an intermediate in the biosynthesis of $\mathbf{4}$ and $\mathbf{5}$, but suggest a cyclopentane monoterpene skeleton as an intermediate in iridoid biosynthesis ${ }^{14}$. In $S$. umbrosa, aucubin can be formed by the sequence: $\mathbf{6} \rightarrow$ geniposidic acid (12) $\rightarrow$ bartisioside (7) by decarboxylation and hydroxylation in the precursor's $\mathrm{C}_{6}$ position ${ }^{13}$.

Damtoft's group ${ }^{15,16}$ demonstrated that 6 is a precursor for some iridoids, however, these findings conflict with others results published in the literature ${ }^{17-19}$. It was found also that deoxyloganic acid (8) was incorporated into asperuloside (9) in Theligonum cynocrambe (Rubiaceae) while 6 was not ${ }^{16}$. It could therefore be deduced that the tricyclic product 9 from the monocyclic monoterpene cyclization was not $\mathbf{1}$, but iridodial $(\mathbf{1 0})^{20}$, meanwhile, in feeding experiments with Gardenia jasminoides (Rubiaceae) cell suspension cultures the following sequence was proved: tarennoside $(\mathbf{1 1}) \rightarrow \mathbf{1 2} \rightarrow$ geniposide (13) $\rightarrow$ gardenoside (14), all of which are formed from $\mathbf{1}^{18,19}$, as well as from $\mathbf{8}^{21}$.
Damtoft $^{15,23,24}$ also reported that $\mathbf{6}$ is a precursor for antirrhinoside (15) in Antirrhinum majus (Scrophulariaceae) and for $\mathbf{5}$ in Plantago major (Plantaginaceae) and Scrophularia racemosa (Scrophulariaceae), thus indirectly demonstrating the intermediacy of $\mathbf{1}$ in these biosynthesis. It has been shown elsewhere that $\mathbf{5}$ may be biosynthesized from loganic acid (16) in Daphniphyllum macropodum (Daphniphyllaceae) and Aucuba japonica (Aucubaceae). ${ }^{21}$ Incorporation of $7-{ }^{3} \mathrm{H}-\log a n i n(17)$ into secologanin (18) and into strictosidine (19) in Catharanthus roseus (Apocynaceae) corroborates that secologanin was formed via loganin ${ }^{22}$. In other studies on the subject it has been shown that secoiridoids are formed through this biosynthetic route $^{3,25,26}$. The iridolactone gibboside (20) is biosynthetized in Patrinia gibbosa from the $\mathbf{1 0}^{27}$.

These evidences mentioned so far indicate that two pathways can be deduced for iridoid glucosides biosynthesis: one involving $\mathbf{1 0}$ as a pivotal precursor and the other involving $\mathbf{1}$ as a key intermediate (Figure 2). However this biosynthetic approach seems to be incoherent since there are compounds with double bonds at $\mathrm{C}_{7}-\mathrm{C}_{8}, \mathrm{C}_{8}-\mathrm{C}_{9}$ e $\mathrm{C}_{8}-\mathrm{C}_{10}$, e.g. 5 may be originated from two different routes ${ }^{13,21}$. Nevertheless this fact has been explained tentatively as the result of phytotoxic effect of the precursor on the plant ${ }^{15}$ or yet, due to the fact that the same iridoid glucoside may be biosynthesized by different cyclization processes in different plant species. Thus contrarily to earlier expectations, the routes leading to the iridane skeleton, in the biosynthesis of iridoids and secoiridoids, can be originated from the iridodial cation ${ }^{5}$ (Figure 3 ).

Jensen ${ }^{20}$ proposes the following question: "The problem is whether cyclization takes place before or after oxidation of the methyl group that eventually becomes an iridoid. Stated another way, the question is whether iridodial or iridotrial is the first cyclized intermediate" The iridodial cation must be the first cyclized intermediate and probably the oxidations of the methyl groups at $\mathrm{C}_{4}$ and $\mathrm{C}_{8}$ take place after the cyclization of pyrane ring. All known iridoids seem to be derived from this iridodial cation that can be stabilized, either by borrowing a proton from one neighboring carbon atom $\left(\mathrm{C}_{7}, \mathrm{C}_{9}\right.$ or $\left.\mathrm{C}_{10}\right)$ or by the entrance of one hydride, leading thus to the five basic biosynthetic pathways: $\mathbf{A}, \mathbf{B}, \mathbf{C}, \mathbf{D}$ and $\mathbf{E}$, the last one being the less common (modified from Uesato ${ }^{6}$, Figure 3 ). The cyclization reaction to form iridoid pyrane ring may results from one of the two routes: route 1 - loss of a proton from carbon 4 leads to the formation of a double bond $\mathrm{C}_{3}-\mathrm{C}_{4}$; consequently the 3-O-carbonyl atom will attach $\mathrm{C}_{1}$ (Figure $4 \mathrm{a}$ ); route 2 - hydride attack on $\mathrm{C}_{1}$ will lead to 1-O-carbonyl atom attack on the $\mathrm{C}_{3}$, yielding the lactone ring (Figure 4b). Secoiridoids are biosynthesized 
A)
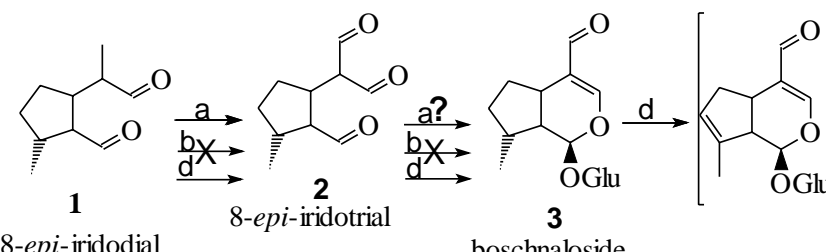

8-epi-iridodial

boschnaloside<smiles>CC1[C@H]2C(CC[C@H]1C)C(I)=CO[C@@H]2O</smiles>

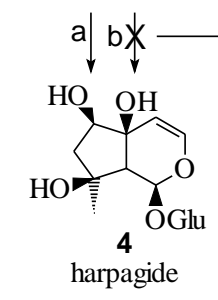

$\mathrm{a} \| \mathrm{b} \mid \mathrm{r}$

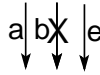<smiles>O=CO</smiles><smiles>CO[C@@H]1CC2CCCC2=CO1</smiles>

8-epi-desoxyloganic acid

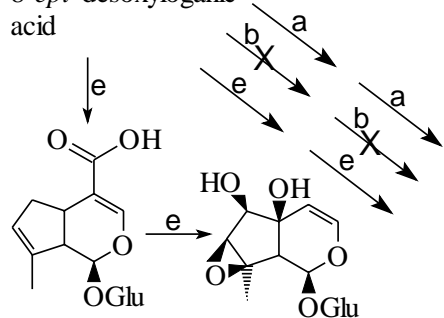
desoxygeniposidic $\mathbf{1 5}$ acid antirrhnoside<smiles>C[Hg]</smiles><smiles>[CH]1CCCC1</smiles>

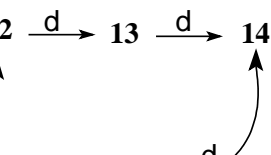

mevalonic acid

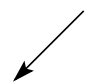<smiles>C1CCCCC1</smiles><smiles>C[C@@H]1CCC2C(C(=O)O)=CO[C@H](O)[C@@H]21</smiles><smiles>CC(C=O)C1CCCC1</smiles>
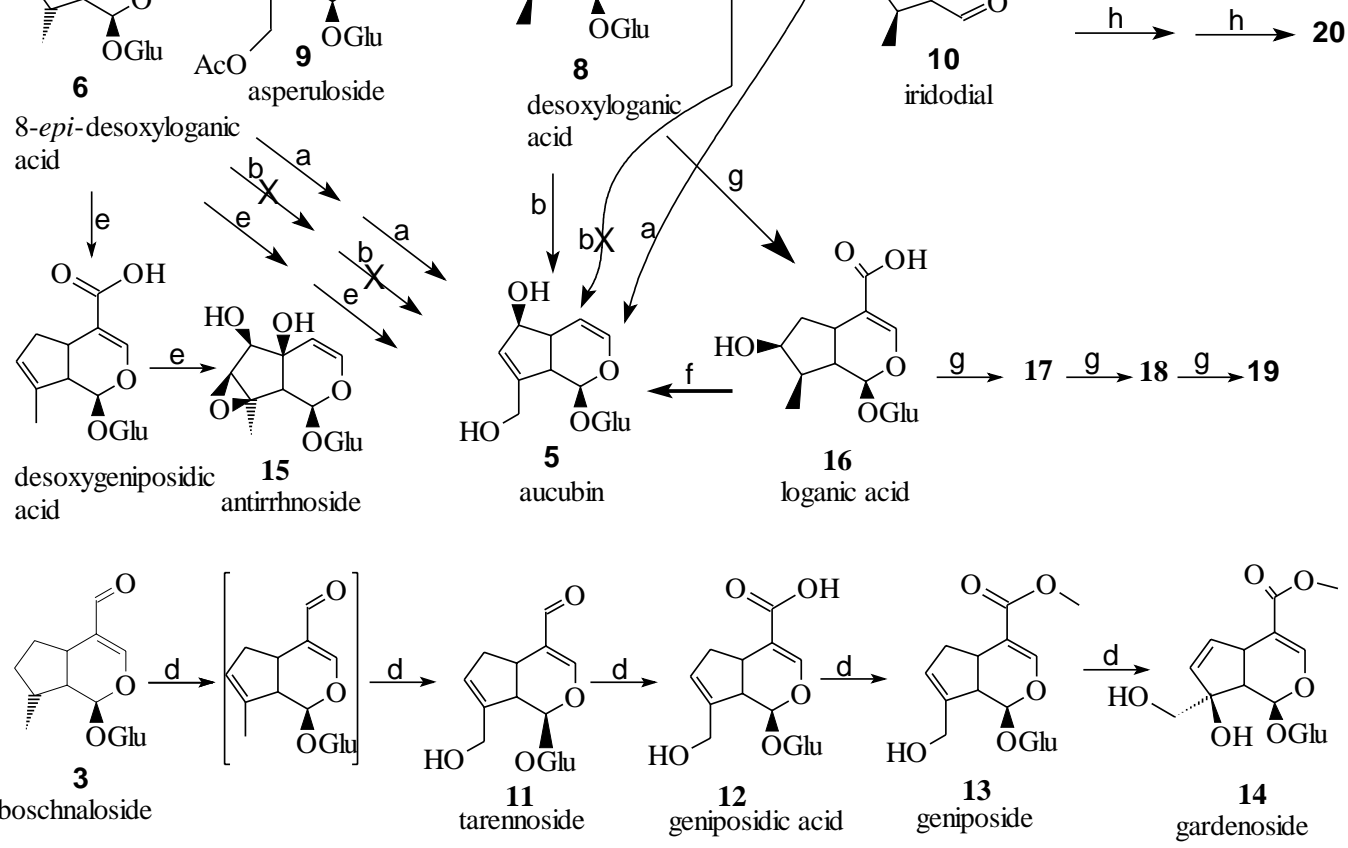

C)

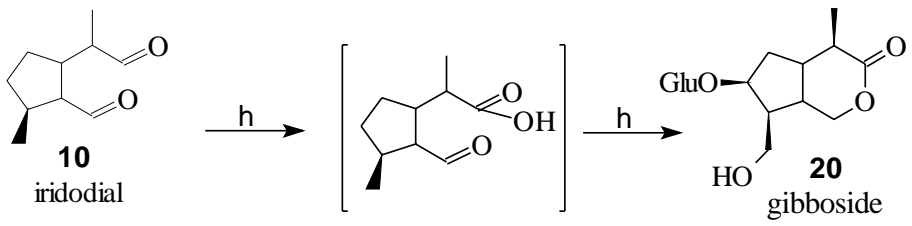

D)

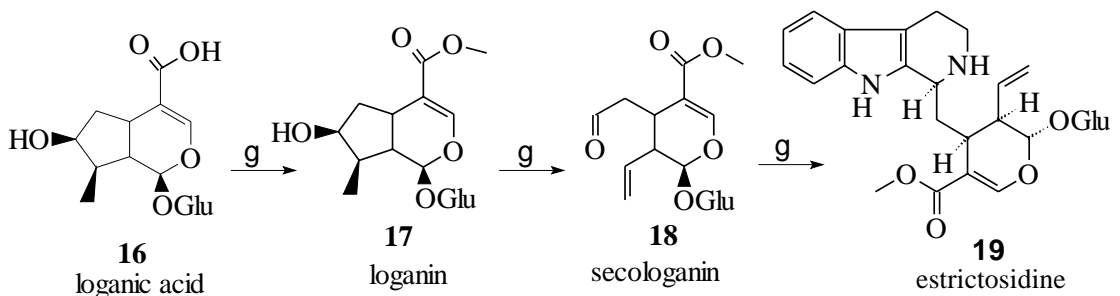

Figure 2. Proposed sequence for the biosynthesis of iridoids. a) Scrophularia umbrosa ${ }^{15}, 16$, b) Buddleya albiflora ${ }^{15}$, c) Theligon cynocrambe ${ }^{20}$, d) Gardenia jasminoides ${ }^{18,19,21}$, e) Antirrhinum majus ${ }^{23}, 24$, f) Daphniphyllum macropodum ${ }^{5}$, Aucuba japonica ${ }^{5}$, g) Catharanthus roseus ${ }^{27}$, and h) Patrinia gibbosa ${ }^{3}$ 


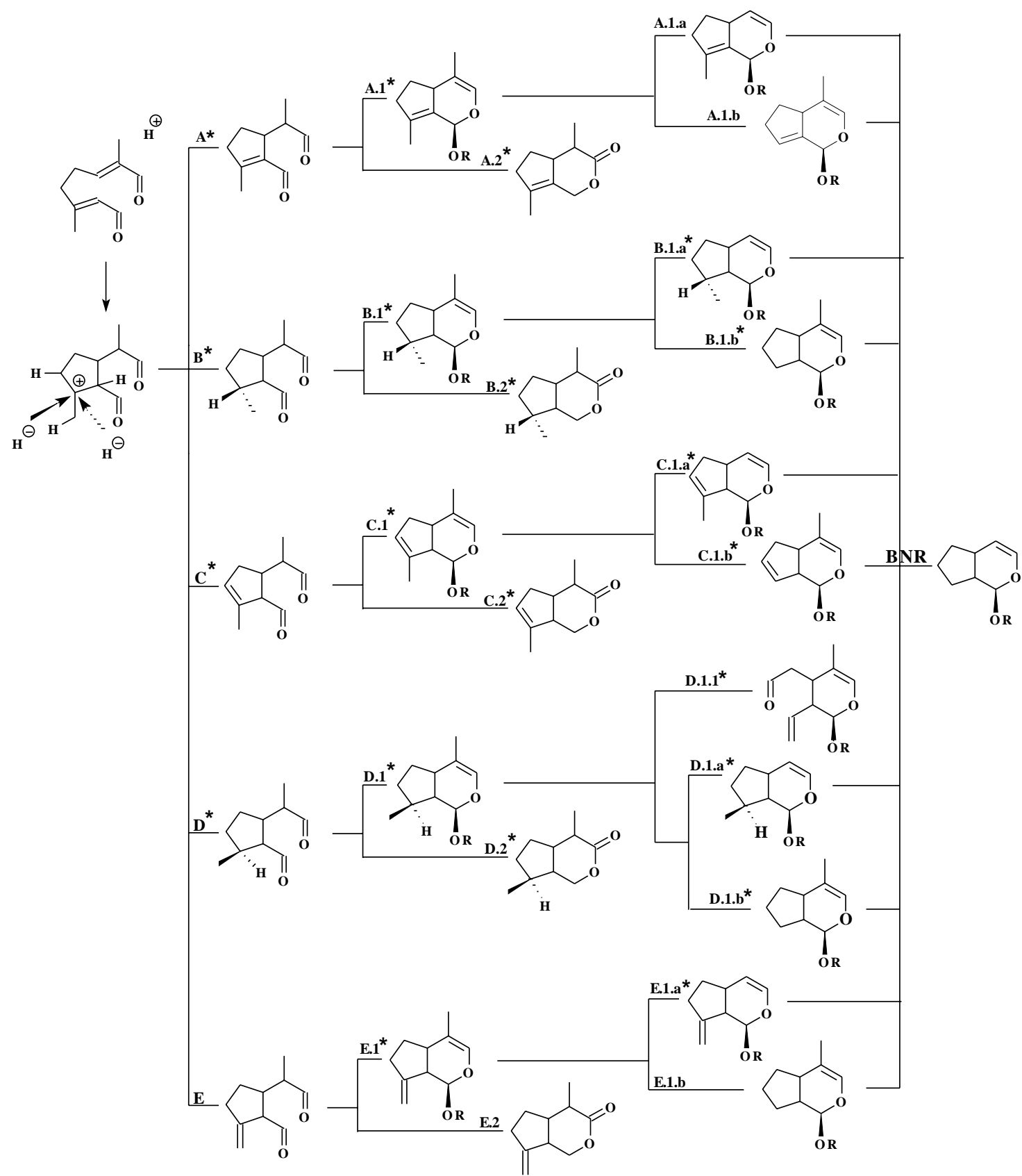

Figure 3. Proposed biogenetic pathways for the iridoid skeleton, the formations of and codes for structural types of iridoids found in Angiospermae $*(\mathrm{R}=$ $\mathrm{H}$ or glucose, $\mathrm{BNR}=$ bisnoriridoids).

exclusively through route $\mathbf{D}$ (from 16, Figure 3). Noriridoids are formed by oxidative decarboxylation on $\mathrm{C}_{10}$ or $\mathrm{C}_{11}$. The noriridoids isolated so far come from route 1 (Figure 3). The very rare bisnoriridoids are also formed by oxidative decarbo-xylation. Routes $\mathbf{A}, \mathbf{C}$ and $\mathbf{E}$ are characterized by forming derivatives with double bonds at $\mathrm{C}_{8}-\mathrm{C}_{9}, \quad \mathrm{C}_{7}-\mathrm{C}_{8} \quad$ and $\mathrm{C}_{8}-\mathrm{C}_{10}$, respectively. Routes $\mathbf{B}$ and $\mathbf{D}$ are represented by components with $\mathrm{C}_{10}$ methyl group oriented in $\alpha$ and $\beta$, respectively.

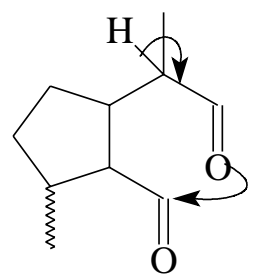

A

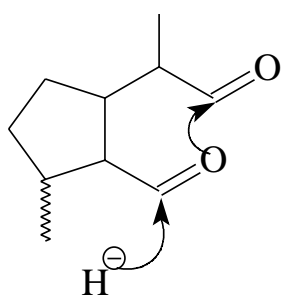

B
Figure 4. Iridane skeleton formation mechanisms. A) Route 1; B) Route 2. 
Table 1. Number of occurrence of iridoids in angiospermic families according to biogenetic route (BNR= bisnoriridoids).

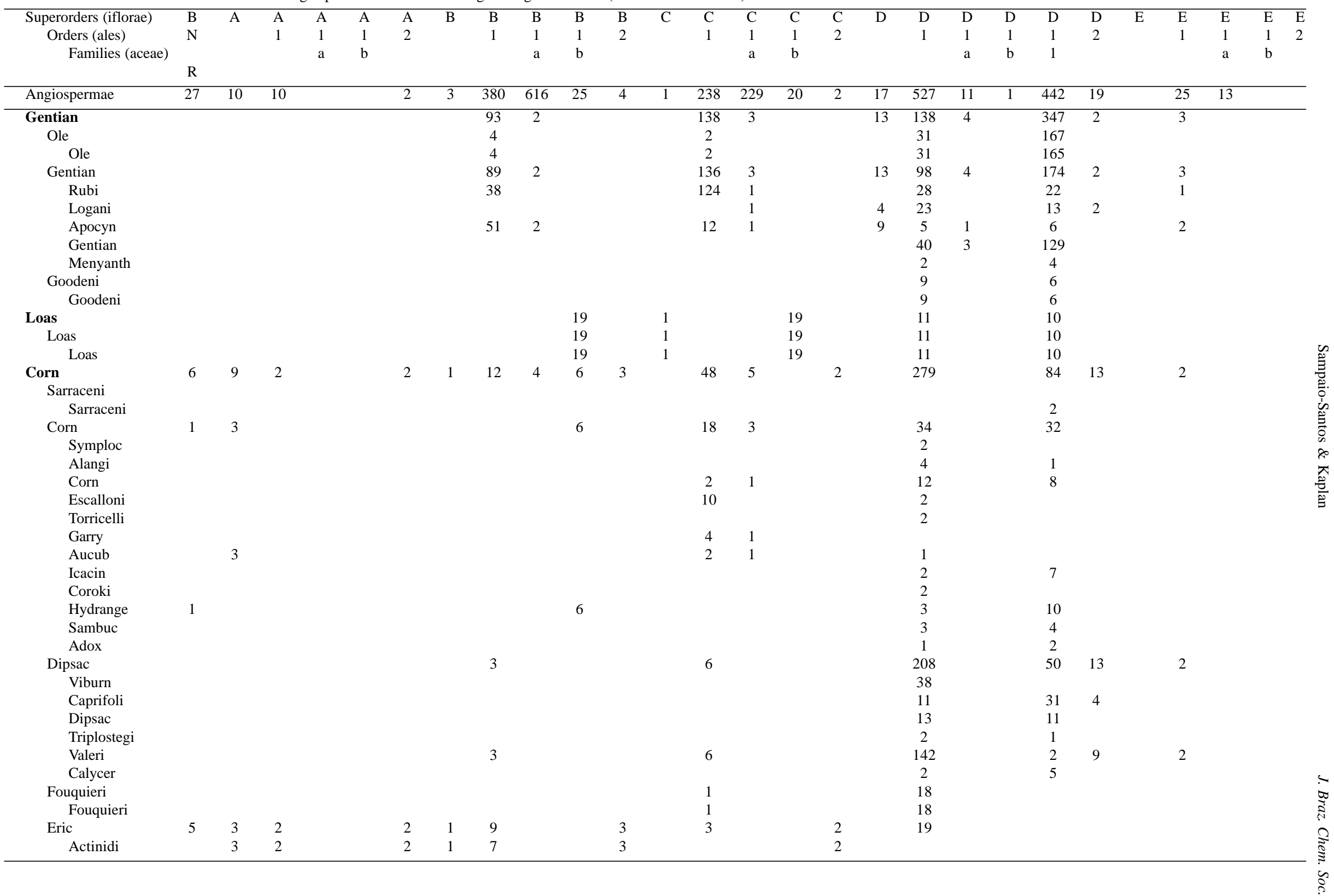


Table 1 (continue)

Superorders (iflorae)

Orders (ales)

Famílies (aceae)

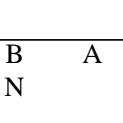

$\begin{array}{ccccc}\mathrm{A} & \mathrm{A} & \mathrm{A} & \mathrm{A} & \mathrm{B} \\ 1 & 1 & 1 & 2 & \\ & \mathrm{a} & \mathrm{b} & & \end{array}$

$\mathrm{R}$
5

Pyrol

Monotrop

Epacrid

Eucommi Eucommi

Lami

crophulari

Buddle

Bignoni

Myopor

Retzi

Globulari

Acanth

Scrophulari

Pedali

Plantagin

Lentibulari

Lami

Verben

Lami

Callitric

Hippurid

Hippurid

Rut

Simaroub

Meli

Polyg

Malpighi

Ros

Bux

Hamamelid

Hamamelid

$\begin{array}{lll} & 3 & \\ & 3 & \\ 21 & 1 & 8 \\ 18 & 1 & 8 \\ 1 & 1 & \\ 5 & & \\ 12 & & \\ & & 8 \\ & & \\ & & \end{array}$

.

.

(1)

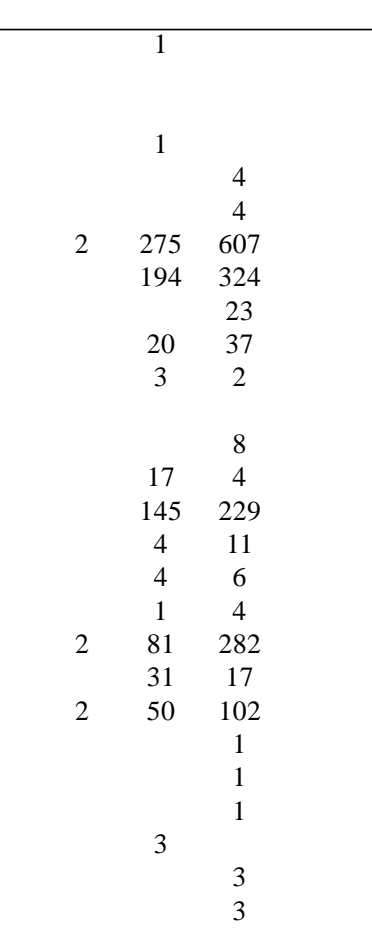

$\begin{array}{ccc}1 & & \\ & & \\ 2 & & \\ 20 & 2 & \\ 20 & 2 & \\ 46 & 221 & 1 \\ 42 & 170 & 1 \\ & 2 & \\ 3 & 8 & \\ & & \\ & & \\ 1 & 4 & \\ 1 & 3 & \\ 33 & 130 & 1 \\ & & \\ 4 & 22 & \\ & 1 & \\ 4 & 40 & \\ 3 & 29 & \\ 1 & 10 & \\ & 1 & \\ & 1 & \\ & 1\end{array}$

\begin{tabular}{|c|c|c|c|c|c|c|c|c|c|c|c|}
\hline $\mathrm{C}$ & $\mathrm{D}$ & $\mathrm{D}$ & $\bar{D}$ & $\mathrm{D}$ & $\mathrm{D}$ & $\bar{D}$ & $E$ & $E$ & $\mathrm{E}$ & $\mathrm{E}$ & $\bar{E}$ \\
\hline 2 & & 1 & 1 & 1 & 1 & 2 & & 1 & 1 & 1 & 2 \\
\hline & & & $\mathrm{a}$ & $\mathrm{b}$ & 1 & & & & $\mathrm{a}$ & $b$ & \\
\hline
\end{tabular}

3

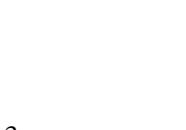


The routes assigned (*) in Figure 3 lead to compounds already isolated from plants. According to this assumption, naturally occurring iridoid derivatives can be considered on biogenetic grounds into 27 groups, already demonstrated or postulated. Stereochemistry considerations and feeding experiments with several ${ }^{2} \mathrm{H}$ and ${ }^{3} \mathrm{H}$-labeled precursors of iridoids were taken into consideration ${ }^{27-34}$. Successive modifications of the cyclopentane ring and the $\mathrm{C}_{11}$ methyl group lead to a great diversity of iridoid skeletons.

\section{Chemosystematics and biosynthesis of iridoids}

Micromolecular chemosystematics is one of the most fashionable and rapidly expanding areas of plant taxonomy and uses chemical information to improve the classification of plants 35 . Chemotaxonomy has much to offer to phytochemists, pharmacists, botanists, taxonomists and even physicians ${ }^{36}$. Another valuable application of the chemosystematics is to support biosynthetic schemes based on the isolated natural products and the labeled precursors informations. In this way it has been possible to unveil biosynthetic pathways that can be useful to explain uncertain positioning of taxa besides phylogenetic tendency of iridoid producing plants ${ }^{37}$. In the above scheme (Figure 3) chemical features can be useful, not only for construction of an evolutionary diagram for iridoids, but also for taxonomic proposal, considering the fact that same compounds are always biosynthesized in the same way.

Over 2500 iridoids have so far been found to occur in nature, the vast majority of them differing only in degree and type of substitution in the basic cyclopentane ring system. However the most distinct chemical feature among them is the biosynthetic derivation explored by the different plant groups.

Table 1 shows occurrence numbers of the produced iridoids in each biosynthetic pathway by the Angiospermae families (sensu Dahlgren) ${ }^{38}$. It is worth to note that the families of Lamiiflorae preferentially produce carbocyclic iridoids (40\%) and noriridoids $(60 \%)$ with the 10-methyl group $\alpha$-oriented (paths B.1 and B.1a; 275 and 607 derivatives, respectively) and having a $\mathrm{C}_{7}-\mathrm{C}_{8}$ double bond (route C.1a; 211 derivatives). On the other hand the iridoid containing families belonging to superorders Corniflorae and Gentianiflorae are specialized in compounds with $\beta$ oriented 10-methyl group (path D.1; 279 and 138 iridoids, respectively) and they are also the secoiridoid containing plants (path D.1.1; 82 and 347 iridoids derivatives, respectively). Loasiflorae with only one family Loasaceae, biosynthesized $64 \%$ of known noriridoids (path B.1b and C.1b; 19 and 19 iridoids, respectively), meanwhile these compounds are quite different from those produced by
Lamiiflorae species since the carbon atoms lost through decarboxylation are different. In Loasiflorae the lost carbon is $\mathrm{C}_{10}$, whereas in Lamiiflorae it is $\mathrm{C}_{11}$. The Loasaceae iridoids are similar to those from Hydrangeaceae (Cornales, Corniflorae), not only as the nor- $\mathrm{C}_{10}$-derivatives, but also as the secoiridoids. One can observe through the biogenetic map that in families with predominance of compounds with $\mathrm{a} \mathrm{C}_{10}$ methyl group $\alpha$-oriented (path B.1,380 iridoids) there is a great tendency to product noriridoids without the $C_{11}$ methyl group (613 iridoids). However families with predominance of $\mathrm{a} \mathrm{C}_{10}$ methyl group $\beta$-oriented (path D.1, 527 iridoids) produce preferentially secoiridoid deriva-tives (path D.1.1, 440 iridoids) (Figures 5-8). The Actinidiaceae family (superorder Corniflorae) shows a great variety of iridoid structural types and explores various of the possible biogenetic routes. The compounds are, however, not much oxygenated and poorly specialized, suggesting the primitiveness of the producing taxon. Thus Actinidiaceae may be considered as the ancestral of the iridoid families. Analyses of the percentual relationships between carbocyclic iridoids/secoiridoids, $\mathrm{C}_{10}$ /nor- $\mathrm{C}_{11}$-iridoids, $\mathrm{C}_{10}$ /nor- $\mathrm{C}_{10^{-}}$ iridoids and $\alpha / \beta$-methyl $\mathrm{C} 10$ iridoids reveal that from Actinidiaceae arises a great monophyletic group represented by two large groups: Actinidiaceae splits into two evolutionary sequences, one towards Eucommiales, formed only by the carbocyclic iridoid and the other towards Cornales. Eucommiales splits into three branches: one towards Ericales, the second one towards Fouquieriales, and the third one via Lamiiflorae (Lamiales $\rightarrow$ Scrophulariales $\rightarrow$ Hippuridales). Cornales which initiate the additional production of secoiridoids give rise to three distinct branches: Loasales; Dipsacales $\rightarrow$ Sarraceniales; and the sequence Gentianales $\rightarrow$ Goodeniales and Oleales (Figure 9).

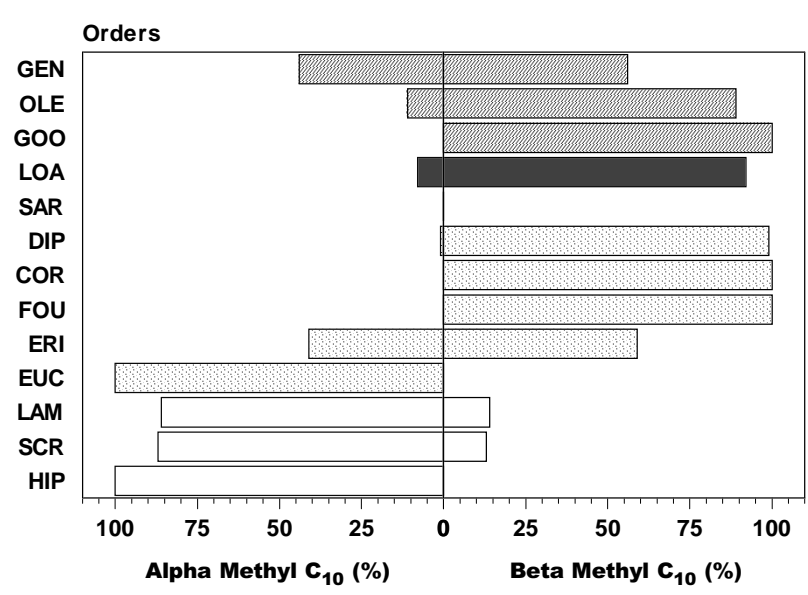

Figure 5. Percentage relations between $\alpha / \beta$-methyl $C_{10}$ in Gentianiflorae (hatched area), Loasiflorae (dark area), Corniflorae (dotted area), and Lamiiflorae (white area). 


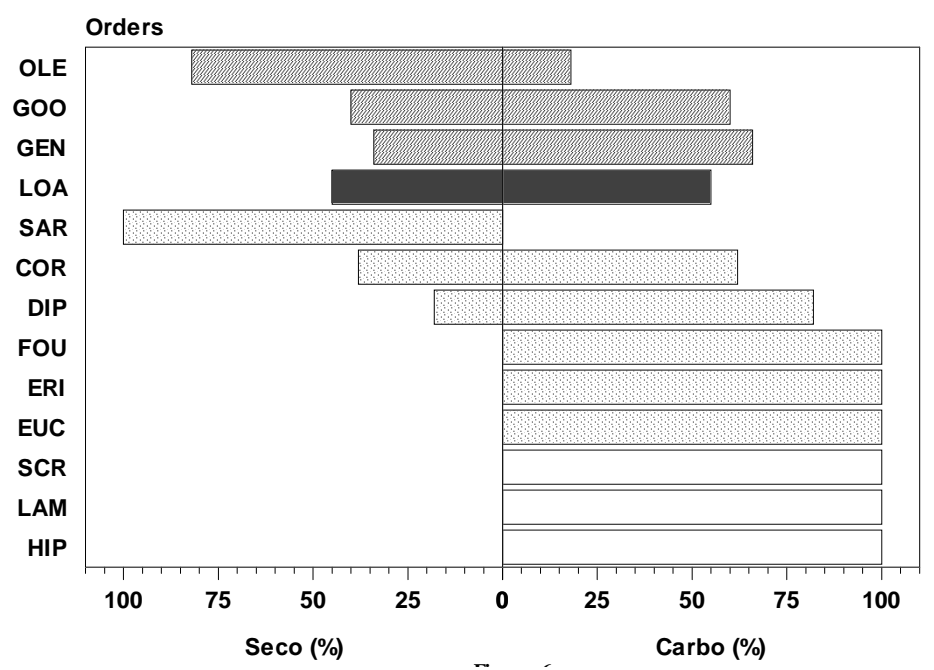

Figure 6. Percentage relations between iridoids carbocyclic iridoids/secoiridoids in Gentianiflorae (hatched area), Loasiflorae (dark area), Corniflorae (dotted area), and Lamiiflorae (white area).

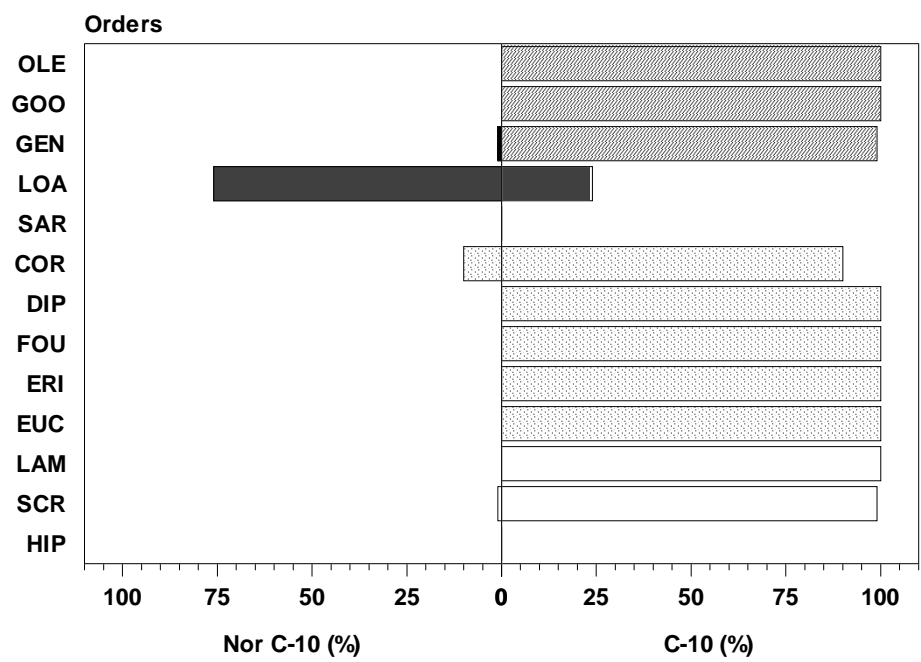

Figure 7. Percentage relations between $\mathrm{C}_{10}$ /nor- $\mathrm{C}_{10}$-iridoids in Gentianiflorae (hatched area), Loasiflorae (dark area), Corniflorae (dotted area), and Lamiiflorae (white area).

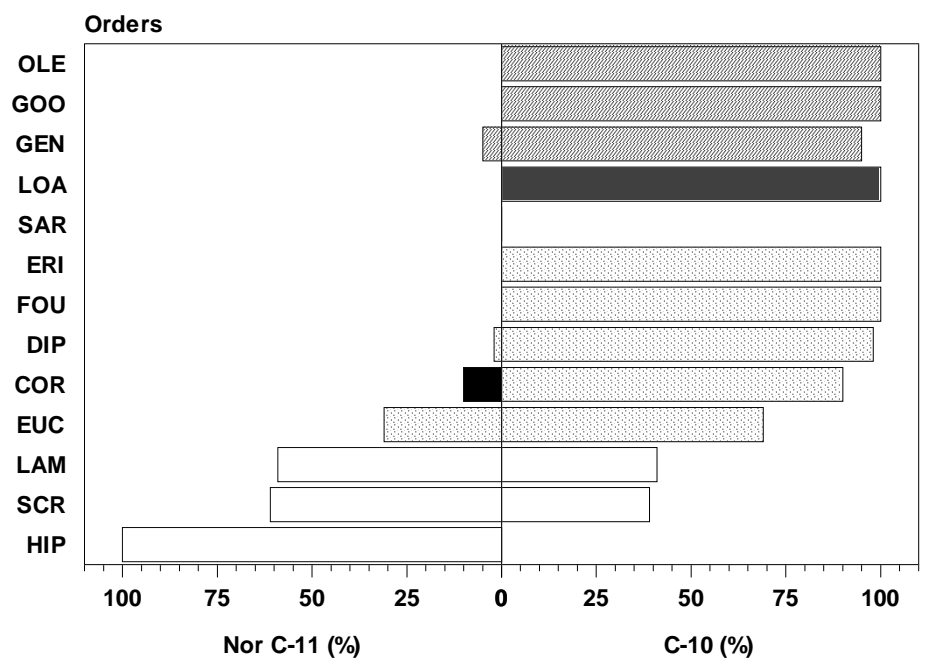

Figure 8. Percentage relations between $\mathrm{C}_{10}$ /nor- $\mathrm{C}_{11}$-iridoids in Gentianiflorae (hatched area), Loasiflorae (dark area), Corniflorae (dotted area), and Lamiiflorae (white area). 


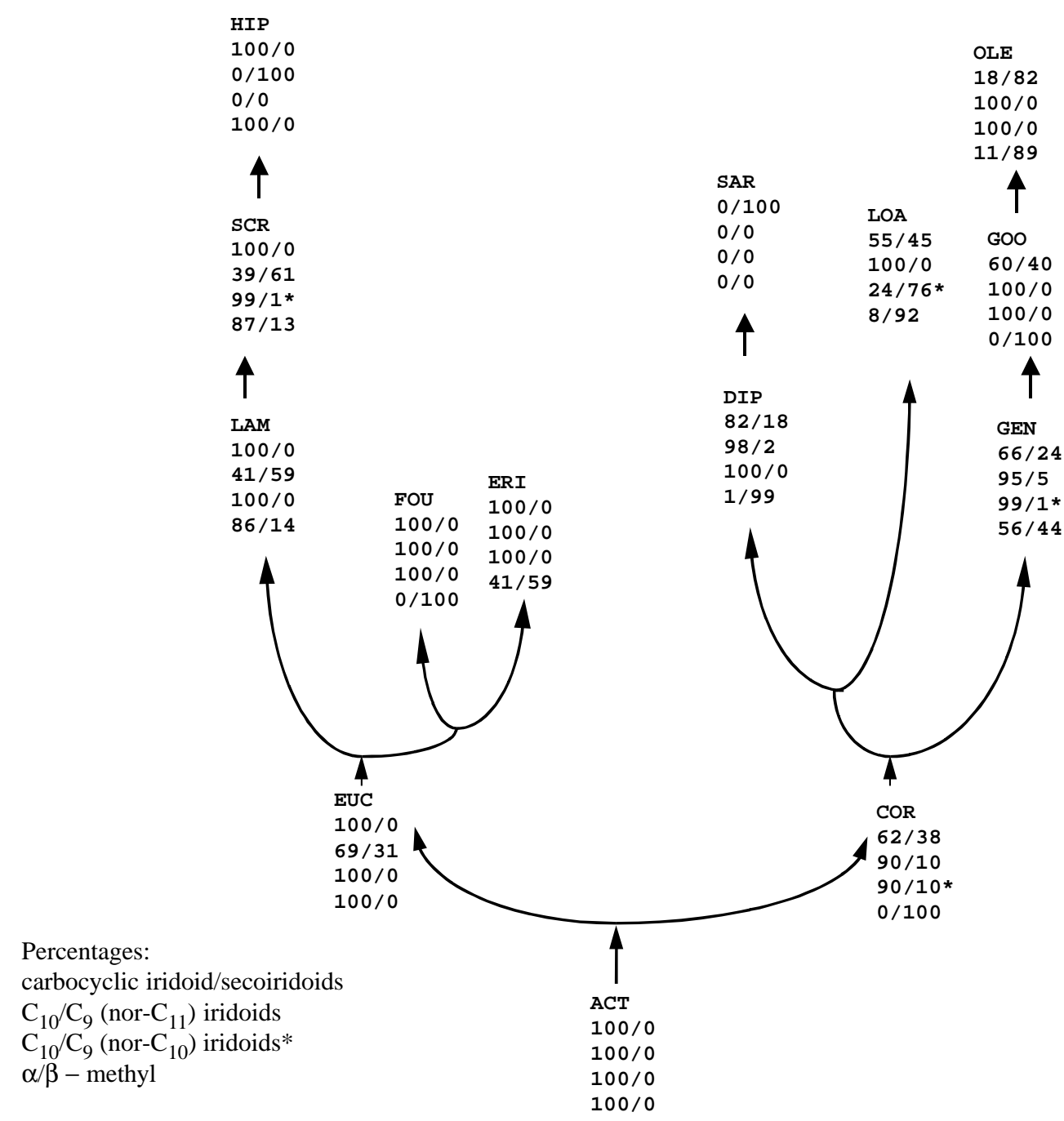

Figure 9. Phylogenetic scheme for iridoid-bearing orders of Angiospermae. ACT, Actinidiaceae; EUC, Eucommiales; FOU, Fouquieriales; LAM, Lamiales; SCR, Scrophulariales; HIP, Hippuridales; ERI, Ericales; COR, Cornales; LOA, Loasales; GEN, Gentianales; GOO, Goodeniales; OLE, Oleales; DIP, Dipsacales; SAR, Sarraceniales.

In conclusion, the number and nature of the iridoids present in Angiospermae can be a measure of the complexity or simplicity of the routes involved in their biosynthesis. In the field of chemosystematics, therefore, the value of iridoid characters shows great relevance in plant classification and phylogeny.

\section{Acknowledgements}

The authors are grateful to CNPq and FAPERJ for financial support.

\section{References}

1. El-Naggar, L. J.; Beal, J. L. J. Nat. Prod. 1980, 46, 649.

2. Junior, P. Planta Med. 1990, 56, 1.
3. Damtoft, S.; Franzyk, H.; Jensen,. S. R. Phytochemistry 1995, 38, 615.

4. Borin, M. R. de M. B.; Gottlieb, O. R. Pl. Syst. Evol. 1993, $184,41$.

5. Inouye, H.; Uesato, S. in "Progress in the Chemistry of Organic Natural Products", L. Zechmeister and W. Herz, eds. (Springer-Verlag, New York) 1986, 50, p. 169.

6. Uesato, S. Yakugaku Zasshi 1988, 108, 381.

7. Inouye, H. in Pharmacognosy and Phytochemistry, eds H. Wagner, and L. Hörhammer, Springer-Verlag, New York, 1971.

8. Cordell, G. A. Lloydia 1974, 37, 219.

9. McGarvey, D. J.; Croteau, R. The Plant Cell. 1995, 7, 1015.

10. Inouye, H.; Ueda, S.; Uesato, S. Phytochemistry 1977, $16,1669$. 
11. Mann, J.; Davidson, R. S.; Hobbs, J. B; Banthorpe, D. V.; Harborne, J. B. in Natural Products - Their Chemistry and Biological Significance, Longman Scientific \& Technical, London, 1994.

12. Waterman, P. G.; Gray, A. I. Nat. Prod. Rep. 1987, 4, 175.

13. Damtoft, S.; Jensen, S. R.; Weiergang, I. Phytochemistry 1994, 35, 621.

14. Damtoft, S.; Jensen, S. R.; Jessen, C. U.; Knudsen, T. B. Phytochemistry, 1993, 33, 1089.

15. Damtoft, S. Phytochemistry 1983, 22, 1929.

16. Damtoft, S.; Jensen, S. R.; Nielsen, B. J. Biochem. Soc. Transactions 1983, 11, 593.

17. Uesato, S. Yakugaku Zasshi 1984, 104, 1232.

18. Uesato, S.; Ueda, S.; Kobayashi, K.; Miyauchi, M.; Inouye, H. Tetrahedron Lett. 1984, 25, 573.

19. Uesato, S.; Ueda, S.; Kobayashi, K.; Miyauchi, M.; Itoh, H.; Inouye, H. Phytochemistry 1986, 25, 2309.

20. Jensen, S. R. in "Ecological Chemistry and Biochemistry of Plant Terpenoids", J.B. Harborne and F.A Thomas-Barberan, eds. (Clarendon Press, Oxford), 1991, p. 133.

21. Inouye, H.; Ueda, H.; Aoki, Y.; Takeda, Y. Tetrahedron Lett. 1969, 2351.

22. Uesato, S.; Matsuda, S.; Inouye, H. Chem. Pharm. Bull. 1984, 32, 1671.

23. Damtoft, S.; Jensen, S. R.; Jensen, C. U., Knudsen, T. B. Phytochemistry 1993, 33, 1087.
24. Damtoft, S.; Jensen, S. R.; Schacht, M. Phytochemistry 1995, 39, 549.

25. Battersby, A. R.; Kapil, R. S.; Martin, J. A.; Mo, L. Chem. Commun. 1968, 133.

26. Inouye, H.; Ueda, S.; Nakamura, Y. Chem. Pharm. Bull. 1970, 2043.

27. Xie, S.; Uesato, S.; Fujita, T.; Inouye, H. J. Nat. Prod. 1989, 52, 701.

28. Battersby, A. R.; Brown, R. T.; Kapil, R. S.; Martin, J. A.; Plunkett, A. O. Chem. Commun. 1966, 812.

29. Battersby, A. R.; Kapil, R. S.; Southgate, R. Chem. Commun. 1968, 131.

30. Brechbühler-Bader, S.; Coscia, C. J.; Loew, P.; Szczepanski, Ch. Von; Arigoni, D. Chem. Commun. 1968, 136.

31. Coscia, C. J.; Guarnaccia, R. Chem. Commun. 1968, 138.

32. Inouye, H.; Ueda, S.; Takeda, Y. Chem. Pharm. Bull. 1972, 20, 1305.

33. Damtoft, S. J. Chem. Soc. Chem. Commun. 1981, 228.

34. Damtoft, S.; Jensen, S. R.; Nielsen, B. J. Phytochemistry 1981, 20, 2717.

35. Stace, C. A. "Plant Taxonomy and Biosystematics", Cambridge University Press, Cambrigde, 1991.

36. Hegnauer, R. Phytochemistry 1986, 25, 1519.

37. Sampaio-Santos, M. I.; Kaplan, M. A. C.; Gottlieb, O. R. An. Acad. bras. Ci. 1995, 67 (Suppl.3), 413

38. Dahlgren, R. M. T. Bot. J. of Linn. Soc. 1980, 80, 91.

Received: May 12, 2000

Published on the web: February 9, 2001 